\title{
Risk factors and causes associated with maternal mortality in a rural tertiary level hospital in Bangladesh
}

\author{
SA Tazri ${ }^{1 凶}$, M Ahmed $^{2}$, MN Shumsun ${ }^{3}$, AM Raza ${ }^{4}$
}

\begin{abstract}
The aim of the study was to find out the risk factors and causes of maternal mortality in rural hospitals of Bangladesh. The retrospective study was conducted at the Department of Obstetrics and Gynaecology, Jahurul Islam Medical College Hospital with duration of 3 years from May 2009 to April 2012. Total number of maternal deaths was 21 yielding the rate of maternal death as 7.0 per 1000 live births during the study period. The risk factors were age ranging from 21 to 25 years, primigravida, low socioeconomic condition, and less antenatal checkup. Eclampsia was the leading cause of death followed by obstetric hemorrhage, unsafe abortion, obstructed labour.
\end{abstract}

Key words: risk factors, causes, maternal mortality, Bangladesh.

\section{Introduction}

The complications of pregnancy and childbirth are the leading causes of death and disability of reproductive age in the developing countries. ${ }^{1}$ Worldwide, over 500000 women and girls die of complications related to pregnancy and childbirth each year. Over $99.0 \%$ of those deaths occur in developing countries. $^{2-4}$ The findings of the nationally representative Bangladesh Maternal Health Services and Maternal Mortality Survey (BMMS) 2010 show that maternal mortality is 194 deaths per 100000 live births. ${ }^{5}$

Three leading causes of maternal death are post partum bleeding $(24.0 \%)$, infection $(15.0 \%)$, unsafe abortion (13.0\%), and others are prolonged labour, obstructed labour, eclampsia and other indirect causes. ${ }^{6}$ Factors associated with maternal mortality are age, parity, socio-economic strata, antenatal care, substandard care, etc. ${ }^{7}$

Bangladesh is one of the developing countries where maternal mortality is still very high and available information which can draw attention to the problem is lacking at this moment. Jahurul Islam Medical College (JIMCH) is a rural tertiary hospital where patients come to receive adequate and prompt treatment particularly when the cases are complicated and there is a risk of death. So, JIMCH has been selected as the study place to analyze the maternal death cases to have an idea on maternal mortality in a rural tertiary hospital.

\section{Materials and Method}

The retrospective study was conducted in the $\mathrm{JIMCH}$ with duration of 3 years period

1. SA Tazri, Assistant Professor of Obstetrics and Gynaecology, Jahurul Islam Medical College, Kishoreganaj. Email: sumiaahmedtazri@gmail.com

2. M Ahmed, Professor of Obstetrics and Gynaecology, Jahurul Islam Medical College, Kishoreganaj

3. MN Shumsun, Assistant Professor of Obstetrics and Gynaecology, Jahurul Islam Medical College, Kishoreganaj

4. AM Raza, Associate Professor of Pathology, Jahurul Islam Medical College, Kishoreganaj 
from May 2009 to April 2012. Data were collected from all patients admitted in the Department of Obstetrics and Gynaecology. Only death cases were enrolled for analysis.

All the death cases in the department during mentioned period were reviewed in details in presence of professors and senior doctors. The necessary information was collected and recorded in a preformed facility based maternal death review form and finally necessary clinical and statistical analyses were done.

\section{Related definitions}

The $10^{\text {th }}$ Revision of the International Classification of Diseases (ICD-10) defines maternal death as death of a woman while pregnant or within 42 days of termination of pregnancy irrespective of duration and site of pregnancy from any cause related to or aggravated by the pregnancy or its management but not from accidental or incidental causes. ${ }^{8}$

According to the ICD-10 maternal deaths can be divided into 2 groups- direct and indirect. Direct obstetric deaths are those resulting from obstetric complications of the pregnant state (pregnancy, labour and puerperium) from interventions, omissions, incorrect treatments, or from a chain of events resulting from any of the above. Severe bleeding/ hemorrhage, infection, unsafe abortions, hypertensive disorders of the pregnancy especially eclampsia and obstructed labour are the common causes of direct maternal death. Indirect obstetric deaths are those resulting from previous existing diseases or that develops during pregnancy and which are not due to direct obstetric causes, but are aggravated by physiologic effects of pregnancy. Indirect causes such as malaria, anemia, HIV/AIDS and cardiovascular diseases which complicate pregnancy.

Late maternal death- a late maternal death is the death of a woman from direct or indirect obstetric causes more than 42 days but less than one year after termination of pregnancy. ${ }^{9}$
Pregnancy related death- the death of a woman while pregnant or within 42 days of termination of pregnancy irrespective of cause of death.

\section{Results}

There were 3200 deliveries of which 3009 babies were born alive; total number of maternal deaths was 21 yielding the rate of maternal death as 7.0 per 1000 live births during the study period. Table 1 shows the important risk factors associated with maternal death. The risk factors were age ranging from 21 to 25 years, primigravida, low socioeconomic condition, and less antenatal checkup.

Table 2 shows the causes of maternal deaths. Analyzing the causes of maternal deaths, it was found that eclampsia (47.6\%) was the leading cause of death. Obstetric hemorrhage (14.3\%) was the second leading cause of maternal death in this study followed by unsafe abortion (9.5\%). The other causes of maternal death were obstructed labour (9.5\%), anemic heart failure $(4.8 \%)$, molar pregnancy $(9.5 \%)$ and anesthetic hazards (4.8\%).

Septicemia was the final cause of death among $9.5 \%$ patients who died from unsafe abortion and obstructed labour (Table 3). Hemorrhagic shock was the final cause of death among $14.3 \%$ patients died due to obstetric hemorrhage (Table 3 and 4). Almost all cases presented late in the hospital when prompt and effective treatment was not enough to save the lives and this was the most important cause of all maternal deaths.

\section{Discussion}

Factors associated with maternal mortality are age, parity, socio-economic strata, antenatal care, and substandard care. ${ }^{7}$ Pregnancies in young adolescents and in women aged 65 years or above are at increased risk. Highest number of maternal death occurs in patients with $1^{\text {st }}$ pregnancy. ${ }^{10}$ Women from low socio economic condition and with poor antenatal care are also at increased risks. 
Table 1. Important risk factors associated with maternal death, $\mathrm{n}=\mathbf{2 1}$

\begin{tabular}{lrr}
\hline Risk factors encountered & Number of patients & $\%$ \\
\hline Age group ranging from 21 to 25 years & 10 & 47.6 \\
Primigravida & 10 & 47.6 \\
Low socioeconomic condition & 15 & 71.4 \\
Less antenatal checkup & 12 & 57.2 \\
\hline $\mathrm{n}$, number. &
\end{tabular}

Table 2. Causes of death, $n=21$

\begin{tabular}{lrr}
\hline Cause of death & Number & $\%$ \\
\hline Eclampsia & 10 & 47.6 \\
Obstetric hemorrhage (APH and PPH) & 03 & 14.3 \\
Unsafe abortion & 02 & 9.5 \\
Obstructed labour & 02 & 9.5 \\
Anemic heart failure & 01 & 4.8 \\
Molar pregnancy & 02 & 9.5 \\
Anesthetic hazards & 01 & 4.8 \\
\hline Total & 21 & 100.0 \\
\hline
\end{tabular}

number; APH, antepartum haemorrhage; $\mathrm{PPH}$, postpartum hemorrhage.

Table 3. Analysis of maternal deaths due to unsafe abortion

\begin{tabular}{rrrrrr}
\hline Para, $\mathbf{n}$ & $\begin{array}{r}\text { Duration of } \\
\text { pregnancy } \\
\text { (weeks) }\end{array}$ & $\begin{array}{r}\text { Performed } \\
\text { by }\end{array}$ & $\begin{array}{r}\text { Primary } \\
\text { complication }\end{array}$ & $\begin{array}{r}\text { Treatment } \\
\text { offered }\end{array}$ & $\begin{array}{r}\text { Final cause of } \\
\text { death, (\%) }\end{array}$ \\
\hline $3-4,2$ & $13-16$ & $\begin{array}{r}\text { Untrained } \\
\text { person }\end{array}$ & Septicemia & S\&E & $\begin{array}{r}\text { Septicemia, } \\
(9.5 \%)\end{array}$ \\
\hline$>4,1$ & $>16$ & $\begin{array}{r}\text { Untrained } \\
\text { person }\end{array}$ & $\begin{array}{r}\text { Hemorrhagic } \\
\text { shock }\end{array}$ & Laparotomy & $\begin{array}{r}\text { Hemorrhagic } \\
\text { shock, (4.8\%) }\end{array}$ \\
\hline
\end{tabular}

$\mathrm{n}$, number; S \& E, suction and evacuation.

Table 4. Analysis of maternal deaths due to APH \& PPH

\begin{tabular}{rrrrrr}
\hline Para, $\mathbf{n}$ & $\begin{array}{r}\text { Gestational } \\
\text { age }\end{array}$ & $\begin{array}{r}\text { Cause of } \\
\text { PPH }\end{array}$ & $\begin{array}{r}\text { Presented } \\
\text { complication }\end{array}$ & $\begin{array}{r}\text { Treatment } \\
\text { offered }\end{array}$ & $\begin{array}{r}\text { Final cause of } \\
\text { death, (\%) }\end{array}$ \\
\hline APH & 37 weeks & $\begin{array}{r}\text { Abruptio } \\
\text { placenta }\end{array}$ & P/V bleeding & LSCS & DIC, (4.8\%) \\
14,1 & Term & $\begin{array}{r}\text { Retained } \\
\text { placenta }\end{array}$ & $\begin{array}{r}\text { Hemorrhagic } \\
\text { shock }\end{array}$ & $\begin{array}{r}\text { Manual } \\
\text { removal of } \\
\text { placenta }\end{array}$ & Hemorrhagic \\
shock, $(9.5 \%)$
\end{tabular}

n, number; APH, antepartum haemorrhage; PPH, postpartum hemorrhage; LSCS, lower segment caesarean section; DIC, disseminated intravascular coagulation. 
Measuring maternal mortality is difficult and complex, and reliable estimates of the dimensions of this problem are not generally available particularly from the developing countries. ${ }^{11}$

There are some cases where death is not always avoidable but there are many deaths which may be avoidable if regular antenatal checkup by well trained health workers, midwives or doctors can be taken to recognize a complication at an early stage managed by taking appropriate measures. Those who are of low socio economic group are usually less educated, cannot receive health care and advice timely during consultation and cannot reach the best available centre. So, it is likely that the number of maternal death is higher among them.

The study demonstrated that maternal mortality is quite high in comparison to other report done on a national basis. This value is very high in comparison to the developed countries. The value was 3.2/1000 live births according BMMS 2001. ${ }^{10}$ In the developed countries the incidence is very low and decreasing in last decades. In some rural parts of Africa, maternal mortality ratio is higher than $1000 / 100000$ live births, in contrast the rate is $10 / 100000$ live births in United Kingdom since 1985. Maternal mortality rate (MMR) in Bangladesh has declined by $66.0 \%$ over last few decades, estimated at a lowering rate of $5.5 \%$ every year. The latest MMR in Bangladesh is 170 per 100000 live births (1.7\% per 1000 live births) as per United Nations and World Health Organization estimates for 2014. ${ }^{11,12}$ The MMR was 600 per 100000 live births in 1975 and 574 in $1990 .{ }^{11,12}$

The results of this study showed high value in JIMCH does not reflect the situation of the whole country as patients came to this tertiary referral hospital especially when the cases became complicated. This may also be due to lack of basic obstetric care, proper antenatal check-ups and obstetric care in the context of rural Bangladesh which should be ensured to reach the already lagging behind millennium development goal by $2015^{13}$ by targeting decline in MMR to 143 per 100000 live birth consequently sustainable development goal.

\section{References}

1. Yorkshire and the Humber Local Supervising Authority. Yorkshire and the Humber Guideline 11. 2007 (Final version).

2. Bulatao RA, Rose JA. Rating maternal and neonatal health services in developing countries. Bull World Health Organ 2002;80(9):721-7.

3. Future Group International, USAID, MEASURE Evaluation Project. The maternal and neonatal programme effort index. 2003.

4. Rose JA, Campbell O, Bulatao RA. The maternal and neonatal programme effort. Trop Med Int Health 2001;6(10):787-98.

5. National Institute of Population Research and Training (NIPORT), MEASURE Evaluation, UNC-CH, USA, ICDDR,B. Bangladesh Maternal Mortality and Health Care Survey 2010. Dhaka, Bangladesh: NIPORT, MEASURE Evaluation, and ICDDR,B; 2012.

6. Nour NM. An introduction to maternal mortality. Rev Obstet Gynaecol 2008; 1(2):77-81.

7. Konar H. Safe motherhood, epidemiology of obstetrics. In: Konar H, editor. Textbook of Obstetrics. 7th ed. Kolkata: Jaypee Brothers Medical Publishers; 2011.

8. World Health Organization. International Statistical Classification of Diseases and Related Health Problems, ICD-10. International Statistical Classification of Diseases and Related Health Problems; 2011.

9. Kean L. Modern maternity care and changing childbirth. In: Clayton GS, Stuart C, Lees C, editors. Obstetrics by Ten Teachers. 17th ed. London: Taylor \& Francis Ltd; 2000.

10.National Institute of Population Research and Training (NIPORT), ORC Macro, Johns Hopkins University and ICDDR,B. Bangladesh Maternal Mortality and Health Care Survey 2001. Dhaka, Bangladesh and Calverton, Maryland (USA): NIPORT, ORC Macro, Johns Hopkins University, and ICDDR,B; 2003. 
11.WHO, UNICEF, UNFPA, World Bank, United Nations Population Division. Trends in maternal mortality: 1990 to 2013. 2014.

12. World Bank. Bangladesh- Reproductive Health at a Glance. 2011. Available from https://olc.worldbank.org/content/bangladesh -reproductive-health-glance (Accessed in December 15, 2017).

13. General Economics Division, Bangladesh Planning Commission, Government of the People's Republic of Bangladesh. Post 2015 development agenda: Bangladesh proposal to UN. 2013.

\section{Suggestion for citation of the above:}

Tazri SA, Ahmed M, Shumsun MN, Raza AM. Risk factors and causes associated with maternal mortality in a rural tertiary level hospital in Bangladesh. Mediscope 2018;5(1):28-32. 